\title{
Food neophobia in Lebanese children: scale validation and correlates
}

\author{
Rayane El Mouallem 1 , Diana Malaeb ${ }^{2,3}$, Marwan Ake ${ }^{2,4}$, Souheil Hallit ${ }^{1,4, *,} \uparrow$ ๑ and \\ Marie-Claude Fadous Khalife ${ }^{1,5, *,} \dagger$ \\ ${ }^{1}$ Faculty of Medicine and Medical Sciences, Holy Spirit University of Kaslik (USEK), Jounieh, Lebanon: ${ }^{2}$ School of \\ Pharmacy, Lebanese International University, Mseitbeh, Beirut, Lebanon: ${ }^{3}$ Life Sciences and Health Department, \\ Paris-Est University, Paris, France: ${ }^{4}$ INSPECT-LB: Institut National de Santé Publique, Epidémiologie Clinique et \\ Toxicologie-Liban, Beirut, Lebanon: ${ }^{5}$ Pediatrics and Neonatology Department, Notre Dame des Secours University \\ Hospital, Byblos, Lebanon
}

Submitted 19 May 2020: Final revision received 24 November 2020: Accepted 6 January 2021: First published online 12 January 2021

\begin{abstract}
Objective: To validate the Food Neophobia Scale (FNS) and determine factors associated with the presence of food neophobia (FN) in a sample of Lebanese children. Design: Cross-sectional study conducted between July and December 2019.

Setting: All Lebanese governorates.

Participants: Parents of Lebanese children aged 2 to 10 years.

Results: Out of 850 questionnaires, 194 were excluded. The mean age of children was $5.34 \pm 2.20$ years $(50.8 \%$ females); 238 (36.4\%) had low neophobia scores ( $\leq 37)$, whereas $219(33.5 \%)$ and 197 (30.1\%) had, respectively, moderate (between 38 and 41) and severe neophobia scores $(\geq 42)$. All items of the FNS were extracted except item 8 and yielded a two-factor solution with Eigenvalues $>1$ (variance explained $=51.64 \%$; Kaiser-Meyer-Olkin $\quad(\mathrm{KMO})$ test $=0.746$; Bartlett's sphericity test $\left.P<0.001 ; \alpha_{\text {Cronbach }}=0.739\right)$. Children who refused initially to eat vegetables $(\beta=5.51)$, fish $(\beta=4.57)$, fruits $(\beta=4.75)$ or eggs $(\beta=2.99)$ and higher parents' instrumental feeding scores $(\beta=0.3)$ were significantly associated with higher neophobia scores, whereas higher parents' encouragement scores $(\beta=-0 \cdot 21)$ were significantly associated with lower neophobia scores in children.

Conclusion: FN is common in children. Neophobic children tend to have lower variety in their diets. One of the ways to lower the levels of neophobia is the use of encouragement by the parents. In contrast, offering a reward to children for them to eat a certain food was associated with more signs of avoidance. More studies should be conducted to evaluate awareness levels concerning FN.
\end{abstract}

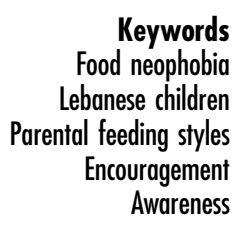

It is well known that humans need a wide variety of foods to meet their essential nutrients' requirements. For children, a well-balanced diet is of extreme importance because they need energy supply and nutrient-dense foods to develop physically and mentally ${ }^{(1)}$. One common concern of parents is the quality of their children's diet. In fact, many of them find it difficult to introduce healthy foods, especially fruits and vegetables, into their children's diet during infancy ${ }^{(2)}$. One of the reasons is many children seem to dislike or refuse the food that is presented to them for the first time. The rejection

${ }^{\dagger}$ Souheil Hallit and Marie-Claude Fadous Khalife are last co-authors. of new or unfamiliar foods is termed food neophobia $(\mathrm{FN})^{(3)}$. It is a normal phase of the development and is not considered pathological ${ }^{(4)}$. Some authors note that FN starts to show at about 18 months of age and it reaches its peak between 2 and 6 years. It then goes to decrease by late childhood and adolescence ${ }^{(5)}$. A French study revealed that almost three-quarters of children aged between 2 and 10 years show a reluctance to try unknown foods ${ }^{(6)}$. Many studies dated back FN to ancient times, when humans were exposed to large amount of toxins and the fear of trying novel foods was a way of protection against ingestion of these harmful substances ${ }^{(7)}$. 


\section{Determinants of food neopbobia}

\section{Sociodemographic characteristics}

Residents of rural areas show higher levels of neophobia compared with urban residents ${ }^{(8)}$. Also, FN levels have been noticed to be related to the level of education of the parents. In fact, the more educated the parents, the less the child will be neophobic ${ }^{(9)}$. Also, studies have shown that when income increases, the levels of neophobia decrease $^{(9)}$. It has been shown that the eating behaviours of others may influence the food choices of children ${ }^{(10)}$. In other terms, neophobic behaviours can be reduced when the child observes others trying the same food.

\section{Previous food experiences}

Breastfed children have also shown more acceptance of vegetables and fruits at an older age ${ }^{(11)}$. The timing of the introduction of solid foods seems to be an important factor in determining later acceptance of fruits and vegetables. The best period to introduce solid foods for better acceptance correlates with the period recommended by the American Academy of Pediatrics (AAP) and by the WHO: between 4 and 6 months of age ${ }^{(12)}$. The earlier a type of food is introduced (before 6 months of age), the easier it will be for the child to accept $\mathrm{it}^{(13)}$.

Furthermore, many parents present with the complaint that their child is refusing to eat new food, and few are aware of the fact that the same food may need to be introduced about 10 to 15 times before the child starts accepting it ${ }^{(14)}$.

\section{Parental feeding styles}

A parenting style is a broad term that describes the type of relationship between a child and his/her parents, the behaviours of the parents towards their children, and the emotional interaction between them. There are four types of parenting styles ${ }^{(15,16)}$ : (1) an authoritarian parent: a parent who is highly demanding of his/her child, with a lot of rules and little regard for the needs of his/her child; (2) an authoritative parent: a parent who is also highly demanding and sets rules but is also highly responsive to the needs of his/her child; (3) an indulgent parent: a parent who is highly responsive, less demanding, with no rules; and (4) a neglectful parent: a parent who is neither demanding nor responsive and doesn't set rules nor listens to his/her child's needs.

Moreover, the different feeding practices that the parents use are thought to be the manifestation of their parenting style during a specific aspect of their life: mealtimes.

Children who have parents that are highly responsive to their preferences showed greater consumption of vegetables compared with those of parents who were not ${ }^{(17)}$. Positive parental styles include but are not limited to the encouragement of the child while feeding, modelling of vegetable intake, well structuring the mealtime, monitoring food intake and using non-food rewards ${ }^{(17,18)}$. Authoritative feeding style is considered one of the best and is correlated with low levels of FN and a better home environment ${ }^{(19)}$.

Caregivers that are uninvolved, strict or extremely permissive negatively affect a child's food consumption and favour neophobic behaviours ${ }^{(17,20)}$. Authoritarian parenting style has been linked with lower vegetable intake and more food rejection in children ${ }^{(21,22)}$. A common method used by parents is the rewarding system: they offer a reward that is usually a food that the child likes on the condition that the child will eat unwanted food ${ }^{(23)}$. Another common method is pressuring and forcing the child to finish his/her food before he/she can leave the table. Studies done on these practices have shown that although they might sometimes increase the consumption of the food immediately, they will end up increasing the rejection of the same food by the child in the long run ${ }^{(24)}$.

\section{Consequences of food neophobia}

Although classified as normal, FN comes with many consequences, especially at higher levels. Research has shown that neophobic children consume a less variety of foods than non-neophobic ones ${ }^{(25)}$. Also, FN increases the risk of chronic diseases. A study that was done on a Finish and Estonian population showed that adults who still showed traits of neophobia ate more food rich in salt and saturated fat, putting them at risk of developing CVD and type 2 diabetes ${ }^{(26)}$. On another note, FN has been associated with stress and frustration during the meal as parents may begin to worry when faced with a child who refuses to eat the food presented to him/her. For this reason, mealtimes can become a cause of conflict for them ${ }^{(27)}$.

\section{Food neophobia $v$. avoidant/restrictive food intake disorder}

Avoidant/restrictive food intake disorder (ARFID) is an eating disorder defined as the avoidance or restriction of foods that result in weight loss or failure to gain weight, deficiency in nutrients, dependency on supplementation and psychosocial changes. Unlike FN, ARFID tends to persist until adulthood $^{(28)}$. Also, FN is not characterised by weight loss or dependence on supplements. Also, there is an entity between FN and ARFID called picky-eating. A picky eater is a child who refuses to eat many familiar as well as unfamiliar foods. His/her diet is usually very selective and limited, as he/she refuses some food textures not just particular foods ${ }^{(4)}$. A lot of researchers seem to believe that these three entities share a common aetiology and that a child with ARFID also manifests high levels of neophobia ${ }^{(28)}$.

Measurements of $\mathrm{FN}$ have not been reported in Lebanon. A common scale used worldwide is the Child Food Neophobia Scale (CFNS), adapted from the Food 
Neophobia Scale (FNS) that was developed in 1992 by Pliner and Hobden ${ }^{(29)}$. Since then, many countries have worked on validating and adapting this questionnaire to their population ${ }^{(30,31,32,33)}$. Hence, it is important to validate the Arabic version of the CFNS to adapt it to our specific population. Since no studies have been done in Lebanon on FN, we aimed to validate the FNS and study the factors associated with FN in children in hopes of shedding the light on it and the ways to deal with it.

\section{Methods}

\section{Sampling and data collection}

In this cross-sectional study conducted between July and December 2019, 850 questionnaires were proportionately distributed across the Lebanese governorates. Children included were those of Lebanese nationality, those between 2 and 10 years of age, those who were born on term and those who lived with both parents. Children with documented food allergies and those who have neurodevelopmental abnormalities were not included. The total number of questionnaires collected was 850, but 194 of them were eliminated and did not make it to the data entry because of the exclusion criteria mentioned above.

\section{Minimal sample size calculation}

Using the Epi Info software (population survey), the minimal sample size needed to have enough statistical power was 544 , taking a $77 \%$ frequency of neophobia according to a previous study ${ }^{(27)}$, a design effect of 2 and a risk of error of $5 \%$.

\section{Questionnaire}

The questionnaire was in Arabic. In the first part, questions concerned the sociodemographic characteristics of each individual: age, gender, BMI, area of living, number of rooms in the house and number of people living in the same house. This part also included information about the parents: their BMI, their level of education and their monthly income.

The second part of the questionnaire focused on the feeding patterns of the child since he/she was born up until this age: whether he/she was breastfed or not, whether he/ she attended kindergarten or not, his/her food dislikes, the method and timing of introduction of solid foods, the place where he/she usually has his/her meals and if he/she sits with his/her family during mealtimes. Some of the questions included about food refusal were: if the child dislikes a food before tasting it, if he/she refuses a certain type of food (specified as vegetables, fruits, fish, meat, etc.), if he/she asks to try before tasting, if he/she refuses certain textures and if he/she is on any supplements. The third and final part asked questions about the feeding style adopted by the parents: whether they are controlling, too permissive, use rewards or encourage their child to eat. The questionnaire included two validated scales that served our study purpose (CFNS in the second part and Parental Feeding Style Questionnaire in the third part).

\section{The child food neophobia scale}

The FNS is a 10-item scale that determines the level of FN in adults. It was developed by Pliner and Hobden in $1992^{(29)}$. In 1994, Pliner adapted this questionnaire to children and it was called the $\mathrm{CFNS}^{(34)}$. Parents of the children are meant to answer the questions. Each question is answered on a Likert scale: ranging from 1 (strongly agree) to 7 (strongly disagree). The minimal score is 10 and the highest is 70 , and higher scores reflected higher levels of neophobia. The CFNS has often been used in the literature to measure the level of neophobia in children ${ }^{(35)}\left(\alpha_{\text {Cronbach }}=0.739\right)$.

\section{The parental feeding style questionnaire}

Parental Feeding Style Questionnaire is a questionnaire that has a total of twenty-seven questions tackling four dimensions of the feeding styles adopted by parents: 'instrumental feeding', 'control over eating, 'encouragement to eat' and 'emotional eating'. The questions regarding emotional eating were omitted in our questionnaire because these questions were not relevant to our dependent variable (FN). The Parental Feeding Style Questionnaire assesses the level of control of the parents regarding their children's meals, the use of instrumental feeding such as offering foods as a reward and the level of encouragement that parents adopt to get their child to eat a refused food. The questions are answered on a 5-point Likert scale (ranging from never to always). Higher levels of each dimension indicate higher use of this method by parents. This specific scale for measuring parental feeding styles has been widely used in many research ${ }^{(36,37)}\left(\alpha_{\text {Cronbach }}=0 \cdot 706\right)$.

\section{Parental attitude score}

Parental attitude score is a tool to evaluate the parent's attitude towards a child's novel food refusal. It was validated to measure different attitudes. It contains actions such as offering the same food multiple times to the child, presenting it with a food that he/she already likes, eating the food with the child at mealtimes and punishing the child when he/she refuses or showing signs of anger in front of the child. Answers were coded on a 5-point Likert scale ranging from 1 (never) to 5 (always). Higher levels mean higher use of the method by parents $\left(\alpha_{\text {Cronbach }}=0.843\right)$.

\section{Forward and back-translation procedure}

One healthcare professional translated from English to Arabic. This forward translation was then translated by a second healthcare professional back to Arabic. No major differences were found between the two English versions, with discrepancies resolved by consensus. A pilot test of the Arabic version was performed on twenty parents, 
before launching data collection. The pilot sample's results were included in the final datasheet.

\section{Statistical analyses}

The statistical data analysis was conducted using the 23rd version of the SPSS software. Two different methods were used to confirm the FNS construct validity. First, factor analysis was run using the principal component analysis technique and run on sample 1 ( $n$ 328). Since the extracted factors were found not to be significantly correlated, the varimax rotation technique was used. To ensure the model's adequacy, the Kaiser-Meyer-Olkin (KMO) measure of sampling adequacy and Bartlett's test of sphericity were calculated. Factors with an Eigenvalue $>1$ were retained. Moreover, Cronbach's $\alpha$ was recorded for reliability analysis for the total scale and its subscales. Second, confirmatory factor analysis was carried out on sample 2 ( $n$ 328). To assess the structure of the instrument, the maximum likelihood method for discrepancy function was used. Several goodness-of-fit indicators were reported: relative chi-square $\left(\chi^{2} / \mathrm{df}\right)$, root mean square error of approximation, goodness-of-fit index and the adjusted goodness-offit index. The index of goodness of fit was calculated by the value of $\chi^{2}$ divided by the $\mathrm{df}\left(\chi^{2} / \mathrm{df}\right)$ (cut-off values $<2-5$ ). The root mean square error of approximation tests the fit of the model to the covariance matrix. As a guideline, values of $<0.05$ indicate a close fit and values below 0.11 an acceptable fit. The goodness of fit index and adjusted goodness-of-fit index are chi-square-based calculations independent of df. The recommended thresholds for acceptable values are $\geq 0 \cdot 90^{(38)}$.

The sample did not have a normal distribution; nonparametric tests were used during the analysis. The Mann-Whitney test was used to compare two means, the Kruskal-Wallis test to compare three or more means, whereas the Spearman correlation test was used for the comparison of continuous variables. Finally, a stepwise linear regression was conducted taking the neophobia score as the dependent variable; independent variables were variables exhibiting a significant association with the neophobia score in the bivariate analysis. A $P<0.05$ was considered significant.

\section{Results}

\section{Sociodemographic and other characteristics}

The mean age of the children was $5.34 \pm 2.20$ years $(50 \cdot 8 \%$ females). The highest percentage of fathers (53.4\%) and mothers $(52.9 \%)$ had a university level of education. Other characteristics are summarised in Table 1 . The mean neophobia score was $39.09 \pm 8.32$; the visual binning option in SPSS showed that $238(36 \cdot 4 \%)$ had low neophobia (scores $\leq 37)$, whereas $219(33.5 \%)$ and $197(30 \cdot 1 \%)$
Table 1 Sociodemographic and other characteristics of the participants $(n 656)$

\begin{tabular}{lrr}
\hline Variable & $n$ & $\%$ \\
\hline Child's gender & & \\
Male & 322 & $49 \cdot 2$ \\
$\quad$ Female & 333 & $50 \cdot 8$ \\
Father's education level & 66 & \\
$\quad$ Illiterate/primary & 109 & $17 \cdot 2$ \\
Complementary & 120 & $19 \cdot 0$ \\
Secondary & 338 & $53 \cdot 4$ \\
$\quad$ University & & \\
Mother's education level & 49 & $7 \cdot 7$ \\
$\quad$ Illiterate/primary & 98 & $15 \cdot 3$ \\
Complementary & 154 & 24.1 \\
Secondary & 338 & 52.9 \\
$\quad$ University & & \\
Family monthly income & 129 & 22.8 \\
$\quad$ <1000 USD & 217 & 38.3 \\
1000-2000 USD & 220 & 38.9 \\
$\quad>2000$ USD & & \\
\hline
\end{tabular}

Table 2 Factor analysis of the Food Neophobia Scale items

\begin{tabular}{lccc}
\hline Variable & $\begin{array}{c}\text { Item } \\
\text { number }\end{array}$ & $\begin{array}{c}\text { Factor } \\
1\end{array}$ & $\begin{array}{c}\text { Factor } \\
2\end{array}$ \\
\hline I like foods from different countries & 4 & 0.792 & \\
I will eat almost anything & 9 & 0.729 & \\
I like to try new ethnic restaurant & 10 & 0.716 & \\
At dinner parties, I will try a new food & 6 & 0.680 & \\
I am constantly sampling new and & 1 & 0.631 & \\
$\quad$ different foods & & & \\
$\begin{array}{l}\text { Ethnic food looks too weird to eat } \\
\text { I am afraid to eat things I have never }\end{array}$ & 7 & 0.552 & \\
$\quad$ had before & & & 0.787 \\
If I do not know what is in a food, I & 3 & & 0.718 \\
$\quad$ will not try it & 2 & & 0.706 \\
I do not trust new foods & & 32.88 & 18.76 \\
$\begin{array}{l}\text { Percentage of variance explained } \\
\text { Cronbach's } \alpha\end{array}$ & 0.739 & 0.783 & 0.650 \\
\hline
\end{tabular}

Factor 1: the absence of neophobia; Factor 2: the presence of neophobia.

had moderate (scores between 38 and 41) and severe (scores $\geq 42$ ) neophobia, respectively.

\section{Exploratory factor analysis}

Sample 1 was used for the factor analysis; all items of the FNS scale were extracted except item 8 and yielded a two-factor solution with Eigenvalues $>1$ (variance explained $=51.64 \% ; \mathrm{KMO}=0.746 ;$ Bartlett's sphericity test $\left.P<0.001 ; \alpha_{\text {Cronbach }}=0.739\right)($ Table 2$)$.

\section{Confirmatory factor analysis}

A confirmatory factor analysis was run on sample 2, using the structure obtained in sample 1 . The following results were obtained: the maximum likelihood chi-square $=209.95$ and $\mathrm{df}=57 \cdot 21$, which gave an $\mathrm{x}^{2} / \mathrm{df}=3.67$. For non-centrality fit indices, the Steiger-Lind root mean square error of approximation was on $0.143(0.125,0.162)$. Moreover, the Joreskog goodness-of-fit index equaled 0.876 and adjusted goodness-of-fit index equaled 0.894 . 


\section{Bivariate analysis}

A significantly higher mean neophobia score was seen in children who do not participate in food purchasing compared with those who do (39.96 v. 38.27), in those who refuse to eat a certain type of food (in general), particularly fruits, legumes, fish and eggs. Furthermore, children whose parents have never introduced each type of solid food alone, those who eat on the dining table rarely and sometimes, those who often eat in their rooms, rarely with their families, and those who always eat while playing (PlayStation, tablet, etc.) had higher neophobia scores in children (Table 3).

Higher control scores $(r=-0 \cdot 117 ; P=0.003)$, higher encouragement scores $(r=-0 \cdot 122 ; P=0.002)$ and higher parents' attitude scores $(r=-0.118 ; P=0.003)$ were significantly, but weakly, associated with lower neophobia, whereas higher instrumental feeding $(r=0.193 ; P<0.001)$ was significantly, but weakly, associated with higher neophobia scores in children. No association was found between age and neophobia $(r=-0.039 ; P=0.324)$. All other variables did not show a significant difference with the neophobia score.

\section{Multivariable analysis}

The results of linear regression, taking the neophobia score as the dependent variable, showed that children who refuse to eat vegetables $(\beta=5.51)$, fish $(\beta=4.57)$, fruits $(\beta=4.75)$, and eggs $(\beta=2.99)$ and higher parents' instrumental feeding scores $(\beta=0 \cdot 3)$ were significantly associated with higher neophobia scores, whereas higher parents' encouragement scores $(\beta=-0 \cdot 21)$ were significantly associated with lower neophobia scores in children (Table 4).

\section{Discussion}

This study is the first of its kind in Lebanon that aims to validate the FNS and evaluate factors associated with FN. Overall, $63.6 \%$ of the children had moderate to severe neophobia; those who refused to eat certain types of foods, specifically fruits, vegetables, fish and eggs and having parents who use rewards to get their children to eat had higher levels of FN. The encouraging attitude adopted by some parents was significantly associated with lower neophobia.

The factor structure obtained was satisfying, dividing the scale's items into the absence and presence of neophobia, with the confirmatory analysis yielding satisfactory results as well. The Cronbach's $\alpha$ value of the Arabic CFNS version was adequate (0.739), but lower than that of previous validated scale's versions: German $(0.79)^{(33)}$, Chinese $(0.91)^{(32)}$, Brazilian Portuguese $(0.916)^{(31)}$ and Italian $(0.89)^{(30)}$. Nevertheless, the Arabic version implies good reliability of the scale in the Lebanese population. Discrepancies related to Cronbach's $\alpha$ values can be related to differences in the perception and patterns of neophobia among different cultures/populations ${ }^{(32)}$. Furthermore, FN was shown to differ between urban and rural areas ${ }^{(8)}$, another possible explanation for this discrepancy.

Our results showed a percentage of $63.6 \%$ of moderate to severe in our children, similar to previous studies. Some studies even noticed that neophobia is highly present until the age of 10 years, then it declines until adolescence or early adulthood ${ }^{(5)}$. As mentioned earlier, one study showed that three-quarters of children aged between 2 and 10 years showed neophobic behaviours ${ }^{(6)}$. Another study done in France revealed $77 \%$ of neophobic children within this age range ${ }^{(27)}$. The high prevalence of neophobia at this age could be due to the fact that children tend to show assertive behaviours and try to establish independence from their parents. Therefore, refusing certain foods is a way to affirm their authority and presence. Another reason for this higher number may be because older children are subject to peer and familial influences making them more prone to accept new foods ${ }^{(10)}$. Also, they are more experienced with food and will not find a lot of novel foods to reject $^{(28)}$. Furthermore, as they grow older, children begin to develop an idea of the importance of eating and having a diversified $\operatorname{diet}^{(39)}$.

Children who had lower variety in their diets, particularly those who ate fewer fruits $(\beta=4.75)$, vegetables $(\beta=5.51)$, fish $(\beta=4.57)$ and eggs $(\beta=2.99)$, showed more neophobic behaviours than those who ate these types of food. These results support the findings of previous research ${ }^{(40,41,42)}$. Many studies talked about the association between less consumption of fruits and vegetables and the presence of neophobia in children ${ }^{(40,41,42)}$. When studying the diet of neophobic children, literature shed the light on the consumption of fruits and vegetables specifically. Not many talked about the attitude towards fish and eggs. These results go with the fact that children dislike bittertasting foods and favour sweet and energy-dense foods ${ }^{(43)}$. Furthermore, some children are genetically determined to dislike bitter foods, which may contribute to the presence of neophobic behaviours ${ }^{(44)}$. Since $\mathrm{FN}$ is common, our results that associate neophobic children with lower consumption of vegetables, fruits, eggs and fish shed the light on the importance of managing neophobic behaviours to help diversify the diet of children. Furthermore, inadequate nutrition and diversification may be risk factors for the development of ARFID.

Additionally, our results showed that parents who used rewards to get their children to eat food, such as promising them a treat or something they like, had children with higher neophobia levels. This is consistent with findings from previous studies ${ }^{(23,24)}$ done on this parental feeding style. Using rewards has been linked with the presence of neophobia ${ }^{(23,24)}$. This might be explained by the fact that when a certain food is promised as a reward for eating an undesired food, this may reinforce the child's negative 
Table 3 Bivariate analysis of factors associated with neophobia

\begin{tabular}{|c|c|c|c|}
\hline \multirow[b]{2}{*}{ Variable } & \multicolumn{3}{|c|}{ Neophobia score } \\
\hline & Mean & & SD \\
\hline \multicolumn{4}{|c|}{ Father's education level } \\
\hline Illiterate/primary & 38.53 & & 6.94 \\
\hline Complementary & 38.23 & & 7.43 \\
\hline Secondary & 38.62 & & $7 \cdot 68$ \\
\hline University & 39.98 & & 8.98 \\
\hline$P$ & \multicolumn{3}{|c|}{0.624} \\
\hline \multicolumn{4}{|c|}{ Mother's education level } \\
\hline Illiterate/primary & 37.65 & & $6 \cdot 79$ \\
\hline Complementary & 38.56 & & 6.92 \\
\hline Secondary & 38.54 & & 7.53 \\
\hline University & 39.81 & & $9 \cdot 18$ \\
\hline$P$ & \multicolumn{3}{|c|}{0.094} \\
\hline \multicolumn{4}{|c|}{ Family monthly income } \\
\hline$<1000$ USD & 38.33 & & $6 \cdot 87$ \\
\hline 1000-2000 USD & 39.27 & & $7 \cdot 13$ \\
\hline$>2000$ USD & 39.34 & & 9.98 \\
\hline$P$ & \multicolumn{3}{|c|}{0.512} \\
\hline \multicolumn{4}{|c|}{ Child participates in food purchasing } \\
\hline No & 39.96 & & $8 \cdot 19$ \\
\hline Yes & 38.27 & & $8 \cdot 36$ \\
\hline$P$ & \multicolumn{3}{|c|}{0.007} \\
\hline \multicolumn{4}{|c|}{ Child refuses to eat a certain type of food (in general) } \\
\hline No & $37 \cdot 19$ & & $7 \cdot 35$ \\
\hline Yes & 41.26 & & 8.86 \\
\hline$P$ & \multicolumn{3}{|c|}{$<0.001$} \\
\hline \multicolumn{4}{|c|}{ Child refuses a certain type of food - fruits } \\
\hline No & 38.60 & & $7 \cdot 86$ \\
\hline Yes & 46.09 & & $11 \cdot 11$ \\
\hline$P$ & & $<0.001$ & \\
\hline Child refuses a cert & & & \\
\hline No & 38.53 & & 8.01 \\
\hline Yes & 44.12 & & 9.33 \\
\hline$P$ & & $<0.001$ & \\
\hline Child refuses a cert & & & \\
\hline No & 38.64 & & $8 \cdot 13$ \\
\hline Yes & $42 \cdot 48$ & & 8.96 \\
\hline$P$ & & 0.001 & \\
\hline Child refuses a cert & & & \\
\hline No & 38.75 & & $8 \cdot 25$ \\
\hline Yes & 43.44 & & 8.04 \\
\hline$P$ & & $<0.001$ & \\
\hline When parents start & & & \\
\hline Never & 41.80 & & $12 \cdot 12$ \\
\hline Rarely & 39.60 & & 10.05 \\
\hline Sometimes & 39.83 & & $7 \cdot 14$ \\
\hline Often & $39 \cdot 24$ & & 7.89 \\
\hline Always & 37.90 & & 8.99 \\
\hline$P$ & & 0.042 & \\
\hline Child eats on the di & & & \\
\hline Never & 39.42 & & $10 \cdot 00$ \\
\hline Rarely & 39.70 & & 8.43 \\
\hline Sometimes & $39 \cdot 70$ & & 7.79 \\
\hline Often & 39.61 & & 8.43 \\
\hline Always & 37.90 & & 8.52 \\
\hline$P$ & & 0.027 & \\
\hline Child eats in his/he & & & \\
\hline Never & 38.66 & & 9.92 \\
\hline Rarely & 39.59 & & 7.73 \\
\hline Sometimes & 39.55 & & $6 \cdot 78$ \\
\hline Often & 39.88 & & $5 \cdot 50$ \\
\hline Always & 34.35 & & $6 \cdot 12$ \\
\hline$P$ & & 0.005 & \\
\hline Child eats with his/l & & & \\
\hline Never & 39.04 & & $4 \cdot 37$ \\
\hline Rarely & 40.75 & & $8 \cdot 27$ \\
\hline Sometimes & 40.06 & & 8.62 \\
\hline
\end{tabular}


Table 3 Continued

\begin{tabular}{|c|c|c|}
\hline \multirow[b]{2}{*}{ Variable } & \multicolumn{2}{|c|}{ Neophobia score } \\
\hline & Mean & $\mathrm{SD}$ \\
\hline Often & $37 \cdot 60$ & 8.41 \\
\hline Always & 38.55 & 8.23 \\
\hline$P$ & \multicolumn{2}{|c|}{0.05} \\
\hline \multicolumn{3}{|c|}{ Child eats while playing (PlayStation, tablet, etc.) } \\
\hline Never & $38 \cdot 19$ & $9 \cdot 10$ \\
\hline Rarely & 38.78 & $7 \cdot 19$ \\
\hline Sometimes & 39.72 & $8 \cdot 14$ \\
\hline Often & 40.91 & 6.94 \\
\hline Always & $41 \cdot 12$ & $9 \cdot 33$ \\
\hline$P$ & \multicolumn{2}{|c|}{0.047} \\
\hline
\end{tabular}

Table 4 Multivariable analysis: linear regression taking the neophobia score as the dependent variable

\begin{tabular}{|c|c|c|c|c|}
\hline Variable & Unstandardised $\beta$ & Standardised $\beta$ & $P$ & $95 \% \mathrm{Cl}$ \\
\hline Child refuses a certain type of food - legumes (yes $v . n^{*}$ ) & $5 \cdot 51$ & 0.20 & $<0.001$ & $3 \cdot 29,7 \cdot 72$ \\
\hline Child refuses a certain type of food - fish (yes $v$. no*) & 4.57 & 0.18 & $<0.001$ & $2.55,6.59$ \\
\hline Parents' instrumental feeding score & 0.30 & 0.13 & 0.001 & $0.12,0.49$ \\
\hline Child refuses a certain type of food - fruits (yes $v . \mathrm{no}^{*}$ ) & 4.75 & $0 \cdot 14$ & 0.001 & $1.97,7.53$ \\
\hline Parents' encouragement score & -0.21 & -0.12 & 0.002 & $-0.35,-0.08$ \\
\hline Child refuses a certain type of food - eggs (yes $v . n^{*}$ ) & 2.99 & 0.09 & 0.018 & $0.51,5.48$ \\
\hline
\end{tabular}

*Reference group.

perception of the non-preferred food and may lead to the child not being willing to eat it in the absence of rewards in the future. Parents may think that this method will make the child consume the refused food because they only see the immediate effect. In the long run, the child will link the food he/she is forced to eat with a bad experience or a punishment, which will further enhance his dislike towards this food $^{(45)}$.

At last, the results showed a negative association between parents who encourage their children to eat the refused food and the level of neophobia; the more encouraging the parents are, the less the children have neophobic behaviours. Reaffirming previous studies, parents who encourage their children to consume or enjoy the mealtime and to try different tastes will not have to deal with neophobia as much as parents who pressure the child to eat his/her meal ${ }^{(17,18)}$. This might be because linking mealtimes to positive experiences discourage neophobia. Mealtimes will not be seen as a punishment, rather a time of bonding between the child and his/her parents. Our results highlight the importance of educating the parents on ways to handle the neophobic behaviours of their children.

\section{Clinical implications}

$\mathrm{FN}$ is common in children, and it concerns the majority of them aged between 2 and 10 years. It is a normal phase of the development of the child, and parents should be aware of it to deal with it the right way. Furthermore, paediatricians should advise the parents during their visits to the best ways to deal with a child who refuses to eat certain types of food. They could advise parents to encourage their children during mealtimes and avoid pressuring them or offering them rewards.

\section{Limitations}

There are some limitations to our research. Since this is a cross-sectional study, it is difficult to evaluate causal relationships. Also, our study type is subject to some biases. Recall bias could have occurred since parents may have incomplete recollections regarding their children's past. Parents could also under- or overestimate a question leading to a nondifferential information bias. Furthermore, some factors such as genetic predisposition and the personality of the child could have acted as confounders since they were not measured but were found in previous studies to affect eating behaviours. Also, the Arabic versions of the questionnaires have not yet been independently validated, but our results point to their having convergent validity. Overall, our results are compatible with the majority of the literature findings. Given the methodology used during the data collection, we believe that our results can be generalised to the whole population.

\section{Conclusion}

FN, or the avoidance of new foods, is a common period in the development of the child. Our results are consistent with those in the literature and prove that neophobia is an important issue that parents have to deal with daily. 
The parent must know the right methods to use to help the child get familiarised with the food. The use of encouraging words and attitudes was found to be associated with low levels of food avoidance in children. In contrast, children who were offered food as a reward to get them to eat showed more signs of avoidance. Using the results of this study in our daily lives, we can help parents worry less about this normal behaviour and offer them ways on how to handle it. Many studies should be conducted in the future to understand the level of awareness of Lebanese parents and paediatricians on $\mathrm{FN}$ and to see if using more encouragement and less instrumental feeding would be an effective intervention.

\section{Acknowledgements}

Acknowledgements: The authors would like to thank all parents for their help in the data collection. Financial support: This study was funded by the Lebanese University. Conflict of interest: The authors disclose no conflicts of interest. Authorship: M.C.F.K. conceived and designed the study. D.M., R.E.M. and M.A. performed the data collection and entry. S.H. involved to data interpretation and statistical analysis. R.E.M. wrote the manuscript. All authors critically revised the manuscript for intellectual content. All authors read and approved the final manuscript. Ethics of human subject participation: This study was conducted according to the guidelines laid down in the Declaration of Helsinki, and all procedures involving human subjects/patients were approved by the Holy Spirit University ethics committee. Written informed consent was obtained from all children's parents.

\section{Availability of data and materials}

There is no public access to all data generated or analysed during this study to preserve the privacy of the identities of the individuals. The dataset that supports the conclusions is available to the corresponding author upon request.

\section{References}

1. Arimond M \& Ruel MT (2004) Dietary diversity is associated with child nutritional status: evidence from 11 demographic and health surveys. J Nutr 134, 2579-2585.

2. Blissett J, Bennett C, Fogel A et al. (2016) Parental modeling and prompting effects on acceptance of a novel fruit in 24 -year-old children are dependent on children's food responsiveness. Br J Nutr 115, 554-564.

3. Birch LL (1999) Development of food preferences. Annu Rev Nutr 19, 41-62.

4. Dovey TM, Staples PA, Gibson EL et al. (2008) Food neophobia and 'picky/fussy' eating in children: a review. Appetite 50, 181-193.
5. Pliner P \& Salvy SJ (2006) Food neophobia in humans. In The Psychology of Food Choice, pp. 75-92 [R Shepherd and M Raats, editors]. Wallingford, UK: CABI.

6. Ayadi K (2006) Préférences alimentaires et socialisation de l'enfant consommateur [Food Preferences and Socialization of Child Consumers]. Groupe ESC Rouen; available at: https://halshs.archives-ouvertes.fr/hal-00605766/ (accessed January 2020).

7. Rozin P, Millman L \& Nemeroff C (1986) Operation of the laws of sympathetic magic in disgust and other domains. J Pers Soc Psychol 50, 703.

8. Flight I, Leppard P \& Cox DN (2003) Food neophobia and associations with cultural diversity and socio-economic status amongst rural and urban Australian adolescents. Appetite 41, 51-59.

9. Meiselman H, King S \& Gillette M (2010) The demographics of neophobia in a large commercial US sample. Food Qual Prefer 21, 893-897.

10. Pliner P \& Salvy S (2006) Food neophobia in humans. Front Nutr Sci 3, 75.

11. Perrine CG, Galuska DA, Thompson FE et al. (2014) Breastfeeding duration is associated with child diet at 6 years. Pediatrics 134, Suppl. 1, S50-S55.

12. Longfier L, Soussignan R, Reissland N et al. (2016) Emotional expressiveness of 5-6 month-old infants born very premature versus full-term at initial exposure to weaning foods. Appetite 107, 494-500.

13. Harris G \& Coulthard H (2016) Early eating behaviours and food acceptance revisited: breastfeeding and introduction of complementary foods as predictive of food acceptance. Curr Obes Rep 5, 113-120.

14. De Cosmi V, Scaglioni S \& Agostoni C (2017) Early taste experiences and later food choices. Nutrients $\mathbf{9}(2), 107$.

15. Shloim N, Edelson LR, Martin N et al. (2015) Parenting styles, feeding styles, feeding practices, and weight status in 4-12 year-old children: a systematic review of the literature. Front Psychol 6, 1849.

16. Garcia OF \& Serra E (2019) Raising children with poor school performance: parenting styles and short- and long-term consequences for adolescent and adult development. Int $J$ Environ Res Public Health 16(7), 1089.

17. Johnson SL (2016) Developmental and environmental influences on young children's vegetable preferences and consumption. Adv Nutr 7, 220S-231S.

18. Yuan WL, Rigal N, Monnery-Patris S et al. (2016) Early determinants of food liking among 5 year-old children: a longitudinal study from the EDEN mother-child cohort. Int $J$ Behav Nutr Phys Act 13, 20.

19. Johnson R, Welk G, Saint-Maurice PF et al. (2012) Parenting styles and home obesogenic environments. Int J Environ Res Public Health 9, 1411-1426.

20. Ventura AK \& Worobey J (2013) Early influences on the development of food preferences. Curr Biol 23, R401-R408.

21. Rigal N (2009) La néophobie alimentaire, un interdit naturel à combattre [Food neophobia, a natural prohibition to fight]. Méd Et Nutr 45, 176-180.

22. Hughes SO, Power TG, Orlet Fisher J et al. (2005) Revisiting a neglected construct: parenting styles in a child-feeding context. Appetite 44, 83-92.

23. Roberts L, Marx JM \& Musher-Eizenman DR (2018) Using food as a reward: an examination of parental reward practices. Appetite 120, 318-326.

24. Galloway AT, Fiorito LM, Francis LA et al. (2006) 'Finish your soup': counterproductive effects of pressuring children to eat on intake and affect. Appetite 46, 318-323.

25. Eertmans A, Victoir A, Vansant G et al. (2005) Food-related personality traits, food choice motives, and food intake: mediator and moderator relationships. Food Qual Pref 16, $714-726$. 
26. Sarin HV, Taba N, Fischer K et al. (2019) Food neophobia associates with poorer dietary quality, metabolic risk factors, and increased disease outcome risk in population-based cohorts in a metabolomics study. Am J Clin Nutr 110 , 233-245.

27. Moret C (2016) La néophobie alimentaire chez l'enfant en crèche [Food neophobia among children in nurseries] Ecole supérieure-Domaine social Valais; available at: https://halshs.archives-ouvertes.fr/hal-00605766/ (accessed January 2020).

28. Dovey TM (2018) Avoidant/restrictive food intake disorder: an eating disorder on a spectrum with food neophobia. In Woodhead Publishing Series in Food Science, Technology and Nutrition, Food Neophobia, pp. 329-349 [S Reilly, editor]. UK: Woodhead Publishing. ISBN 9780081019313. doi: 10.1016/B978-0-08-101931-3.00016-1.

29. Pliner P \& Hobden K (1992) Development of a scale to measure the trait of food neophobia in humans. Appetite 19, 105-120.

30. Laureati M, Bergamaschi V \& Pagliarini E (2015) Assessing childhood food neophobia: validation of a scale in Italian primary school children. Food Qual Pref 40, 8-15.

31. de Andrade Previato HDR \& Behrens JH (2015) Translation and validation of the Food Neophobia Scale (FNS) to the Brazilian Portuguese. Nutr Hosp 32, 925-930.

32. Zou J, Liu Y, Yang Q et al. (2019) Cross-cultural adaption and validation of the Chinese version of the Child Food Neophobia Scale. BMJ Open 9, e026729.

33. Rossbach S, Foterek K, Schmidt I et al. (2016) Food neophobia in German adolescents: determinants and association with dietary habits. Appetite 101, 184-191.

34. Pliner P (1994) Development of measures of food neophobia in children. Appetite 23, 147-163.

35. Rhee KE, Lumeng JC, Appugliese DP et al. (2006) Parenting styles and overweight status in first grade. Pediatrics 117, 2047-2054.
36. Jansen E, Mallan KM, Nicholson JM et al. (2014) The feeding practices and structure questionnaire: construction and initial validation in a sample of Australian first-time mothers and their 2-year olds. Int J Behav Nutr Phys Act 11, 72 .

37. Özçetin M, Yılmaz R, Erkorkmaz Ü et al. (2010) Reliability and validity study of parental feeding style questionnaire. Turk Arch Pediatr 45, 124-131.

38. Marsh HW, Hau K-T \& Wen Z (2004) In search of golden rules: comment on hypothesis-testing approaches to setting cutoff values for fit indexes and dangers in overgeneralizing $\mathrm{Hu}$ and Bentler's (1999) findings. Struct Equ Model 11, 320-341.

39. Birch LL \& Fisher JO (1998) Development of eating behaviors among children and adolescents. Pediatrics 101, 539-549.

40. Larson N \& Story M (2009) A review of environmental influences on food choices. Ann Behav Med 38, Suppl. 1, S56-S73.

41. Ball K, Timperio AF \& Crawford DA (2006) Understanding environmental influences on nutrition and physical activity behaviors: where should we look and what should we count? Int J Behav Nutr Phys Act 3, 33.

42. Guzek D, Głąbska D, Mellová B et al. (2018) Influence of food neophobia level on fruit and vegetable intake and its association with urban area of residence and physical activity in a nationwide case-control study of Polish adolescents. Nutrients 10, 897.

43. Cowart BJ (1981) Development of taste perception in humans: sensitivity and preference throughout the life span. Psychol Bull 90, 43.

44. Mennella JA, Pepino MY \& Reed DR (2005) Genetic and environmental determinants of bitter perception and sweet preferences. Pediatrics 115, e216-e222.

45. Lobos P \& Januszewicz A (2019) Food neophobia in children. Pediatr Endocrinol Diabetes Metab 25, 150-154. 